DOI: https://doi.org/10.24127/ajpm.v9i4.3181

\title{
PENGARUH EDMODO TERHADAP PEMAHAMAN KONSEP MATEMATIKA DAN KEMANDIRIAN BELAJAR MAHASISWA
}

\author{
Rafika Dewi Satriani ${ }^{1 *}$, Muhammad Nur Wangid ${ }^{2}$, Purwono PA ${ }^{3}$ \\ ${ }^{1 *, 2}$ Pendidikan Dasar, Program Pascasarjana, Universitas Negeri Yogyakarta, Indonesia \\ ${ }^{3}$ Pendidikan Guru Sekolah Dasar, Universitas Negeri Yogyakarta, Indonesia \\ *Corresponding author. Jalan Colombo No. 1 Depok, Sleman, 55281, Yogyakarta, Indonesia. \\ E-mail: $\quad$ rafikadewi.2019@student.uny.ac.id ${ }^{1 *)}$ \\ m_nurwangid@uny.ac.id ${ }^{2)}$ \\ purwono@uny.ac.id ${ }^{3)}$
}

Received 20 October 2020; Received in revised form 13 December 2020; Accepted 27 December 2020

\begin{abstract}
Abstrak
Tujuan dari studi ini yakni untuk menguji pengaruh positif edmodo terhadap pemahaman konsep matematika serta kemandirian dalam belajar pada mahasiswa Pendidikan Guru Sekolah Dasar Universitas Negeri Yogyakarta secara terpisah dan secara bersama-sama. Penelitian ini merupakan penelitian kuasi eksperimen. Desain dalam penelitian ini memakai pretest-postest control group design. Sampel penelitian ini yakni 70 Mahasiswa Pendidikan Guru Sekolah Dasar Universitas Negeri Yogyakarta. Sampel ditentukan menggunakan teknik cluster random sampling. Teknik pengumpulan data menggunakan tes pemahaman konsep matematika dan angket kemandirian belajar. Analisis data dilakukan dengan pengujian hipotesis menggunakan uji t dan uji MANOVA. Hasil penelitian memperlihatkan: (1) Ada pengaruh positif edmodo terhadap pemahaman konsep matematika mahasiswa berdasarkan taraf sig $0,00<0.05$; (2) Ada pengaruh positif edmodo terhadap dan kemandirian belajar mahasiswa berdasarkan taraf sig $0,00<0.05$; (3) Ada pengaruh positif edmodo terhadap pemahaman konsep matematika dan kemandirian belajar mahasiswa berdasarkan taraf sig $0,00<0.05$.
\end{abstract}

Kata kunci: e-learning; edmodo; kemandirian belajar; pemahaman konsep matematika

\begin{abstract}
The purpose of this study is to examine the positive effect of Edmodo on understanding mathematical concepts and self regulated learning in students of Primary School Teacher Education Universitas Negeri Yogyakarta separately and collectively. This research is a quasi-experimental research. The design in this study used a pretest-posttest control group design. The sample of this research is 70 students of Primary School Teacher Education Universitas Negeri Yogyakarta. The sample was determined using cluster random sampling technique. The data collection technique used a test of understanding mathematical concepts and a questionnaire for independent learning. Data analysis was performed by testing the hypothesis using the t test and MANOVA test. The results showed: (1) There is a positive effect of Edmodo on students' understanding of mathematical concepts based on the sig level $0.00<0.05$; (2) There is a positive effect of Edmodo on and independent learning of students based on the sig level $0.00<0.05$; (3) There is a positive effect of Edmodo on the understanding of mathematical concepts and student learning independence based on the sig level $0.00<0.05$.
\end{abstract}

Keywords: e-learning ; edmodo; self regulated learning; understanding mathematical concepts

This is an open access article under the Creative Commons Attribution 4.0 International License

\section{PENDAHULUAN}

Matematika bukan hanya sekedar mata pelajaran formal saja, namun lebih dalam lagi, matematika berguna untuk kesuksesan akademis, ekonomi dan bermanfaat dalam kehidupan (Edwards, 2007); (Rittle-Johnson et al., 2019); (Topçu et al., 2016). Menimbang 
matematika begitu penting dalam kehidupan manusia, sudah seharusnya penguasaan konsep dalam matematika dipahami secara tepat dan benar. Pada bidang studi matematika, pemahaman konsep adalah satu dari beberapa kecakapan matematis yang perlu dimiliki oleh siswa agar sukses belajar dalam matematika dan merupakan komponen penting dari kecakapan matematika (Kilpatrick \& Swafford, 2001); (NCTM, 2000); (Cozad \& Riccomini, 2016).

Pada saat pandemi Coronavirus Disease (Covid-19) ini, pembelajaran dilakukan secara daring. Studi pendahuluan yang dilakukan menunjukkan bahwa model belajar yang dipakai dosen kurang variatif, yaitu hanya menggunakan Whatsapp Group dan mengandalkan fitur chat serta unggah gambar untuk menyampaikan materi. Keterbatasan fitur yang digunakan dalam penyampaian materi mengakibatkan dosen memiliki proses diskusi yang kurang terarah dan media yang terbatas untuk membelajarkan konsep matematika. Sehingga mahasiswa sulit untuk memahami konsep-konsep dalam matematika yang diberikan dosen. Hasil wawancara mahasiswa didapat informasi bahwa mahasiswa hanya mengandalkan materi yang diberikan oleh dosen dalam proses belajarnya. Mahasiswa juga mengungkapkan bahwa belajar tentang konsep matematika hanya saat perkuliahan berlangsung dan ketika akan diadakan ujian saja.

Model pembelajaran yang digunakan dosen dapat mempengaruhi pemahaman konsep mahasiswa, namun, mahasiswa juga tidak bisa sepenuhnya hanya mengandalkan pembelajaran dari dosen. Oleh karena itu, mahasiswa harus memiliki kemampuan belajar mandiri agar lebih memahami materi sehingga pemahaman konsep matematikanya dapat maksimal. Setiap aspek kehidupan sangat membutuhkan kemandirian belajar, begitu juga dalam bidang aspek akademik, utamanya pada bidang studi matematika (Berger, 2011).

Kemampuan untuk dapat mengontrol aspek kognitif, emosi dan sikap untuk beradaptasi dalam lingkungan belajar dan lingkungan social untuk mencapai tujuan disebut dengan kemandirian belajar (Berger, 2011); (Blaustein \& Kinniburgh, 2019). Mahasiswa yang memiliki kemandirian belajar akan lebih konsentrasi ketika belajar sehingga apa yang sedang dipelajarinya akan lebih mudah dipahami. Kemandirian belajar bagi mahasiswa merupakan syarat untuk menjadi lulusan profesional (Hidayati \& Listyani, 2010). Hal tersebut menjelaskan kemandirian belajar penting dimiliki oleh mahasiswa agar mampu merencanakan serta mengevaluasi proses belajarnya agar tujuan belajarnya dapat tercapai.

Berdasarkan paparan di atas, mengindikasikan bahwa diperlukan alternatif baru dalam proses belajar mengajar yang sedang berlangsung dimana mahasiswa dapat memiliki kesempatan untuk belajar secara mandiri serta diskusi yang terarah menggunakan platform e-learning yang memiliki berbagai fitur untuk membelajarkan konsep matematika.

Salah satu platform e-learning yang dapat dimanfaatkan yaitu edmodo. Edmodo dapat diakses melalui situs www.edmodo.com, dan melalui aplikasi di smartphone. Edmodo merupakan sebuah jejaring sosial terbesar untuk pendidikan yang memiliki lebih dari 46.000.000 pengguna untuk saling terhubung, berkolaborasi dan belajar (Trust, 2017); (Collins, 2016). Edmodo juga merupakan media diskusi 
asynchronous online dimana dosen dan mahasiswa dapat berpartisi aktif mendiskusikan teks, gambar, audio dan video serta terlibat dalam forum diskusi yang nyaman, otentik dan nyata (Dewi, 2014); (Al-Said, 2015); (Pardede, 2019). Edmodo menarik dan efektif untuk berdiskusi. Partisipasi dan diskusi mahasiswa dapat dengan mudah dipantau melalui akun dosen. Dosen dapat melihat dan melacak semua diskusi melalui kolom komentar (Tran Ngoc Giang, 2014). Sehingga proses diskusi menjadi lebih terarah.

Edmodo merupakan learning management system (LMS) yang unik dan interaktif sehingga pembelajaran online menjadi menarik, menyenangkan, dan memotivasi (Ateş Çobanoğlu, 2018). Hal ini sejalan dengan penelitian Pratama \& Ismiyati (2019) di mana pembelajaran dengan memanfaatkan edmodo dapat membuat mahasiswa lebih aktif dan mandiri dalam perkuliahan.

Hasil penelitian lain yang berkaitan dengan edmodo adalah penelitian Ompusunggu \& Sari (2019) yang menyatakan bahwa dengan belajar melalui edmodo, mahasiswa memiliki kemampuan komunikasi matematika yang lebih baik dan bersikap positif terhadap pembelajaran. Penelitian lainnya yaitu oleh Charoenwet \& Christensen (2016) yang memberikan hasil penelitian yaitu pembelajaran menggunakan edmodo dapat meningkatkan kemampuan belajar mandiri dan partisipasi siswa dalam pembelajaran online secara signifikan. Hasil penelitian oleh Amalina \& Warmansyah (2020) memaparkan bahwa proses belajar dengan e-learning berbantuan edmodo bisa mengakibatkan hasil belajar matematika meningkat.

Tujuan penelitian ini yakni untuk menguji pengaruh positif e-learning berbantuan edmodo terhadap pemahaman konsep matematika dan kemandirian belajar mahasiswa secara terpisah dan secara bersama-sama.

\section{METODE PENELITIAN}

Penelitian ini memakai metode kuantitatif berbentuk quasi experiment (eksperimen semu). Terdapat dua kelas pada penelitian ini, yakni kelas eksperimen dan kontrol. Mahasiswa kelas eksperimen diberikan perlakuan dengan menggunakan e-learning berbantuan edmodo dalam proses belajar. Mahasiswa kelas kontrol diberikan pembelajaran melalui WhatsApp Group. Penelitian ini dilaksanakan di Universitas Negeri Yogyakarta (UNY) pada program studi Pendidikan Guru Sekolah Dasar (PGSD) semester IV pada tanggal 2 April hingga 23 April 2020. Populasi dalam penelitian ini yakni mahasiswa kelas C sebanyak 35 mahasiswa dan kelas F sebanyak 35 mahasiswa, sehingga total 70 mahasiswa.

Sampel ditentukan melalui teknik cluster random sampling. Sampel untuk penelitian ini yaitu kelas $\mathrm{C}$ yang menjadi kelas penerima perlakuan (eksperimen) serta kelas F sebagai kelas yang tidak diberi perlakuan (kelas kontrol). Desain pada penelitian ini memakai pretest-postest control group design seperti pada tabel 1. (Sugiyono, 2016: 76)

Tabel 1. Rancangan Penelitian.

\begin{tabular}{llll}
\hline $\mathrm{KE}$ & $\mathrm{O}_{1}$ & $\mathrm{X}$ & $\mathrm{O}_{2}$ \\
$\mathrm{KK}$ & $\mathrm{O}_{3}$ & --- & $\mathrm{O}_{4}$ \\
\hline
\end{tabular}

Teknik tes dan non tes digunakan sebagai teknik untuk mengumpulkan data pada studi ini. Sedangkan Instrumen pengumpulan data yang akan dipakai yakni tes dan angket. Instrumen tes dipakai dengan tujuan mengetahui 
pemahaman konsep matematika mahasiswa berbentuk soal pre-test dan post-test dalam wujud pilihan ganda (pilgan) dan uraian (esay). Instrumen angket berupa lembar angket kemandirian belajar oleh Hidayati \& Listyani (2010).

Teknik analisis deskriptif dan inferensial digunakan dalam penelitian ini guna analisis data. Untuk mendeskripsikan karakteristik variabel penelitian melalui skor rerata, standar deviasi, dan varians digunakan analisis deskriptif. Sedangkan analisis inferensial untuk melihat efek edmodo pada pemahaman konsep serta kemandirian dalam belajar mahasiswa. Uji yang dilakukan antara lain:

1. Uji normalitas menggunakan Kolmogorov-Smirnov dengan SPSS Statistic 26 sebagai uji prasyarat dalam melakukan uji $\mathrm{t}$ dan uji MANOVA yang bertujuan mengetahui normalitas data pre-test dan post-test.

2. Uji homogenitas menggunakan melalui Lavene Test dengan SPSS Statistic 26 untuk uji prasyarat bagi uji $t$ dan uji MANOVA dengan tujuan untuk melihat kehomogenan data hasil pre-test serta post-test.

3. Uji-t (Independent Sample T-test) bertujuan menguji dampak edmodo pada pemahaman konsep matematika serta kemandirian belajar mahasiswa secara terpisah.

4. Uji Multivariat Analysis of Variance (MANOVA) dengan rumus $T^{2}$ Hotteling untuk menguji dampak edmodo pada pemahaman konsep matematika serta kemandirian belajar mahasiswa secara bersamasama.

Sebelum melakukan uji MANOVA dan uji Independent T-test dilakukan uji sebagai syarat analisis yakni uji normalitas data serta uji homogenitas. Bila hasil dari pengujian normalitas menggunakan KolmogorovSmirnov menunjukkan taraf sig >0,05 maka data dikatakan memiliki distribusi normal. Sebaliknya jika taraf sig $<0,05$ berarti data memiliki distribusi yang tidak normal. Uji homogenitas dengan Lavene Test jika memiliki taraf sig $>0,05$ maka data tergolong homogen. Sebaliknya, data tidak tergpolong homogen jika memiliki taraf sig <0,05. Jika uji prasyarat analisis normalitas dan homogenitas terpenuhi, maka selanjutnya dilakukan pengujian hipotesis dengan uji-t. Jika taraf sig dari hasil uji $\mathrm{t}<0,05$ maka $\mathrm{H}_{0}$ tidak terdukung dan $\mathrm{H}_{1}$ terdukung. Selanjutnya dilakukan uji MANOVA. Jika nilai signifikansi hasil uji MANOVA $<0,05$ berarti $\mathrm{H}_{0}$ tidak terdukung dan $\mathrm{H}_{1}$ otomatis terdukung.

\section{HASIL DAN PEMBAHASAN}

Hasil pada studi yang dilaksanakan mulai tanggal 2 April hingga 23 April 2020 pada mahasiswa semester IV kelas $\mathrm{C}$ dan $\mathrm{F}$ di Universitas Negeri Yogyakarta Program studi PGSD ini meliputi analisis deskriptif serta inferensial. Analisis deskriptif bermaksud untuk memaparkan data hasil post-test dan pre-test pada variabel pemahaman konsep matematika serta kemandirian belajar mahasiswa kelas eksperimen dan kontrol yang meliputi skor rerata, standar deviasi dan varians dalam bentuk deskriptif. Secara deskriptif pemahaman konsep matematika mahasiswa melalui perhitungan rerata skor pre-test dan post-test pada kedua kelas dapat diamati pada Tabel 2 . Sedangkan rerata skor pemahaman konsep matematika mahasiswa kelas kontrol dan eksperimen untuk lebih jelas dapat diihat pada Gambar 1. 
DOI: https://doi.org/10.24127/ajpm.v9i4.3181

Tabel 2. Hasil analisis deskriptif pemahaman konsep matematika kelas eksperimen dan kontrol.

\begin{tabular}{cccccc}
\hline \multirow{2}{*}{ No } & \multirow{2}{*}{ Deskriptif } & \multicolumn{2}{c}{ Pre-test } & \multicolumn{2}{c}{ Post-test } \\
\cline { 3 - 6 } & & KE & KK & KE & KK \\
\hline 1 & Mean & 68.74 & 68.97 & 83.22 & 72.28 \\
2 & $\begin{array}{c}\text { Stand. } \\
\text { Dev }\end{array}$ & 7.64 & 8.25 & 6.71 & 6.83 \\
3 & Varians & 58.43 & 68.20 & 45.12 & 46.68 \\
\hline
\end{tabular}

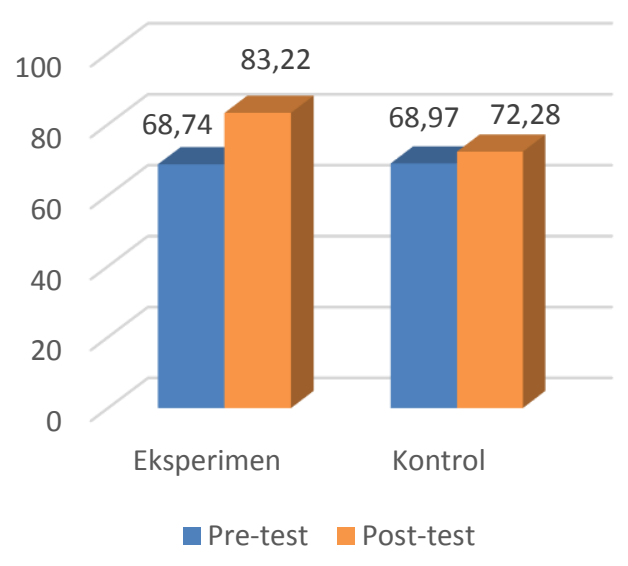

Gambar 1. Rerata skor pemahaman konsep matematika.

Bersumber pada Gambar 1 dapat diketahui bahwa mahasiswa kelas eksperimen memiliki rata-rata peningkatan skor untuk pemahaman konsep matematika sebesar 14.48, yakni dari 68.74 menjadi 83.22. Sedangkan mahasiswa kelas kontrol memiliki peningkatan rata-rata pada skor pemahaman konsep matematika sebesar 3.31, yakni dari 68.97 menjadi 72.28. Arti dari hasil perhitungan menunjukkan mahasiswa kelas ekperimen memiliki peningkatan yang lebih tinggi rerata skor pemahaman konsep matematika daripada kelas kontrol. Berikutnya hasil analisis deskriptif kemandirian belajar mahasiswa melalui perhitungan ratarata skor pre-test serta post-test pada kelas kontrol dan eksperimen bisa diamati pada Tabel 3.

Tabel 3. Hasil analisis deskriptif variabel kemandirian belajar kelas eksperimen dan kontrol.

\begin{tabular}{cccccc}
\hline \multirow{2}{*}{ No } & \multirow{2}{*}{ Deskriptif } & \multicolumn{2}{c}{ Pre-test } & \multicolumn{2}{c}{ Post-test } \\
\cline { 3 - 6 } & & KE & KK & KE & KK \\
\hline 1 & Mean & 69.40 & 71.34 & 79.80 & 74.43 \\
2 & Stand. Dev & 5.71 & 4.09 & 4.28 & 4.37 \\
3 & Varians & 32.60 & 16.70 & 18.34 & 19.13 \\
\hline
\end{tabular}

Skor rata-rata kemandirian belajar mahasiswa pada kedua kelas untuk lebih jelasnya diilustrasikan pada Gambar 2.

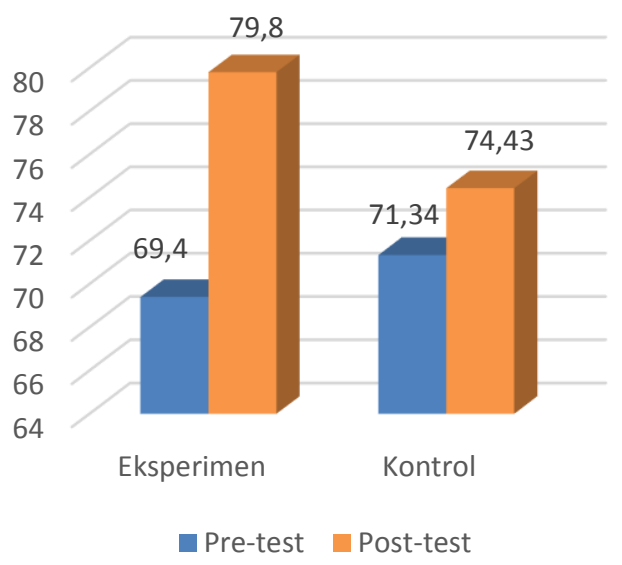

Gambar 2. Rerata skor kemandirian belajar.

Bersumber pada Gambar 2 dapat dilihat bahwa mahasiswa kelas eksperimen memiliki rata-rata peningkatan skor kemandirian belajar 10.4, yakni dari 69.4 menjadi 79.8 . Sedangkan mahasiswa kelas kontrol memiliki peningkatan rata-rata skor kemandirian belajar sebesar 3.09, yakni dari 71.34 menjadi 74.43. Arti dari hasil perhitungan menunjukkan mahasiswa kelas ekperimen memiliki peningkatan rerata skor kemandirian belajar yang lebih tinggi dibandingkan kelas kontrol. 
DOI: https://doi.org/10.24127/ajpm.v9i4.3181

Sebelum dianalisis secara inferensial yang bertujuan melihat pengaruh e-learning berbantuan edmodo terhadap pemahaman konsep matematika serta kemandirian belajar, dilakukan uji asumsi, yakni uji normalitas serta homogenitas terlebih dahulu. Uji normalitas memiliki hasil seperti yang tertera pada Tabel 4 dan Tabel 5.

Tabel 4. Uji normalitas pre-test.

\begin{tabular}{cccc}
\hline \multirow{2}{*}{ No } & Data & \multicolumn{2}{c}{ Nilai sig. } \\
\cline { 3 - 4 } & & Eksperimen & Kontrol \\
\hline 1 & $\begin{array}{c}\text { Pemahaman } \\
\text { konsep }\end{array}$ & 0.200 & 0.200 \\
& Kemandirian & 0.200 & 0.200 \\
\hline & Belajar & & \\
\hline
\end{tabular}

Tabel 5. Uji normalitas post-test.

\begin{tabular}{cccc}
\hline \multirow{2}{*}{ No } & Data & \multicolumn{2}{c}{ Nilai sig. } \\
\cline { 3 - 4 } & Eksperimen & Kontrol \\
\hline 1 & $\begin{array}{c}\text { Pemahaman } \\
\text { konsep }\end{array}$ & 0.200 & 0.200 \\
& $\begin{array}{c}\text { Kemandirian } \\
\text { Belajar }\end{array}$ & 0.200 & 0.200 \\
\hline
\end{tabular}

Dari Tabel 4 dan Tabel 5 didapati infromasi bahwa hasil pengujian normalitas data kedua variabel pada kedua kelas mempunyai taraf sig. $>0.05$, jadi data dikatakan memiliki distribusi normal.

Analisis homogenitas dengan Lavene Test bisa diamati pada Tabel 6 .

Tabel 6. Uji Homogenitas

\begin{tabular}{ccc}
\hline No & Data & Nilai sig. \\
\hline 1 & Pre-test & 0.618 \\
2 & Post-test & 0.798 \\
\hline
\end{tabular}

Berdasarkan Tabel 6 hasil dari uji homogenitas melalui Lavene Test memperlihatkan nilai sig $>0.05$ yang berarti masing-masing variabel kedua kelas homogen. Karena telah memenuhi uji prasyarat analisis yang membuktikan data memiliki distribusi normal dan kedua kelas homogen kemudian berikutnya uji hipotesis dilaksanakan dengan uji t dan MANOVA.

Uji-t bertujuan untuk melihat pengaruh positif edmodo terhadap pemahaman konsep matematika dan kemandirian belajar mahasiswa secara terpisah. Hasil uji-t tertera pada Tabel 7.

\begin{tabular}{clccc}
\multicolumn{4}{c}{ Tabel 7. Hasil uji Independent T-test } \\
\hline Kondisi & Variabel & $\mathbf{t}_{\text {hitung }}$ & $\boldsymbol{D f}$ & Sig \\
\hline Pretest & $\begin{array}{l}\text { Pemahaman } \\
\text { konsep }\end{array}$ & 0.978 & 68 & 0.332 \\
& $\begin{array}{l}\text { Kemandirian } \\
\text { belajar }\end{array}$ & -1.637 & 68 & 0.107 \\
Posttest & $\begin{array}{l}\text { Pemahaman } \\
\text { konsep }\end{array}$ & 5.078 & 68 & 0.000 \\
& $\begin{array}{l}\text { Kemandirian } \\
\text { belajar }\end{array}$ & 4.992 & 68 & 0.000 \\
\hline
\end{tabular}

Berdasarkan Tabel 7 diketahui jika seluruh nilai signifikansi pada pretest $>0.05$ maka, bisa ditarik kesimpulan tidak ada perbedaan kelas kontrol dan eksperimen. Sedangkan nilai signifikansi untuk post-test kedua variabel adalah <0.05 yang berarti ada perbedaan antara kedua kelas. Sesuai dengan hasil tersebut maka $\mathrm{H}_{0}$ tidak terdukung, dan secara otomatis $\mathrm{H}_{1}$ terdukung. Jadi kesimpulannya yakni (1) ada pengaruh positif pembelajaran dengan edmodo terhadap pemahaman konsep matematika; (2) ada pengaruh positif pembelajaran menggunakan edmodo terhadap kemandirian belajar mahasiswa. Dengan kata lain pemahaman konsep matematika serta kemandirian belajar mahasiswa yang memanfaatkan e-learning berbantuan edmodo memiliki nilai rerata yang lebih tinggi daripada nilai rerata mahasiswa yang menerapkan pembelajaran melalui WhatsApp. 
DOI: https://doi.org/10.24127/ajpm.v9i4.3181

Setelah diketahui bahwa $e$ learning berbantuan edmodo mempunyai dampak positif terhadap pemahaman konsep matematika dan kemandirian belajar mahasiswa secara terpisah, selanjutnya dilakukan uji
MANOVA untuk mengetahui pengaruh penggunaan edmodo terhadap pemahaman konsep matematika dan kemandirian dalam belajar mahasiswa secara bersamaan. Berikut hasil uji MANOVA dapat dilihat pada Tabel 8.

Tabel 8. Hasil uji MANOVA

\section{Multivariate Tests $^{a}$}

\begin{tabular}{llccccc}
\hline Effect & & Value & $\boldsymbol{F}$ & $\begin{array}{c}\text { Hypothesis } \\
\boldsymbol{d f}\end{array}$ & $\begin{array}{c}\text { Error } \\
\boldsymbol{d f}\end{array}$ & Sig. \\
\hline Kelas & & & 2 & 67.000 & .000 \\
& Pillai's Trace & .410 & $23.251^{\mathrm{b}}$ & 2 & 67.000 & .000 \\
& Wilks' Lambda & .590 & $23.251^{\mathrm{b}}$ & 2 & 67.000 & .000 \\
& Hotelling's Trace & .694 & $23.251^{\mathrm{b}}$ & 2 & 67.000 & .000 \\
& Roy's Largest & .694 & $23.251^{\mathrm{b}}$ & 2 & & \\
\hline
\end{tabular}

Dari Tabel 8 didapati taraf sig menunjukkan $0,000<0,05$. Sehingga $\mathrm{H}_{0}$ tidak terdukung, dan $\mathrm{H}_{1}$ terdukung. Hasil dari uji MANOVA mengungkapkan bahwa ada perbedaan dalam hal pemahaman konsep matematika dan kemandirian belajar kelas eksperimen dibandingkan kelas kontrol. Oleh sebab itu kesimpulan dari hasil tersebut yakni ada pengaruh positif pembelajaran menggunakan edmodo terhadap pemahaman konsep matematika dan kemandirian belajar mahasiswa.

Hasil penelitian menunjukkan bahwa penggunaan $e$-learning berbantuan edmodo terbukti memiliki pengaruh positif terhadap pemahaman konsep matematika. Pengaruh positif didasarkan pada adanya peningkatan pemahaman konsep matematika mahasiswa sebelum dan sesudah pembelajaran menggunakan edmodo. Selain itu, hasil studi ini juga menunjukkan bahwa pembelajaran menggunakan edmodo membawa dampak positif terhadap pemahaman konsep matematika dan kemandirian belajar mahasiswa secara bersamasama.
Hal ini dikarenakan pembelajaran menggunakan edmodo membuat diskusi lebih terarah sehingga mahasiswa mudah memahami materi yang disampaikan. Diskusi yang terarah memiliki nilai tambah kognitif yang memberi mahasiswa kesempatan untuk membangun dan berbagi pengetahuan sehingga mencapai hasil yang baik pada tes pemahaman konsep matematika. penggunaan e-learning berbantuan edmodo melalui forum diskusi yang terarah mampu meningkatkan keefektifan pembelajaran (Cheng et al., 2011); (Enriquez, 2014). Edmodo sangat membantu untuk meningkatkan pemahaman mahasiswa karena efektifitas edmodo sebagai jejaring sosial pendidikan (Nasrullah et al., 2018). Melalui e-learning berbantuan edmodo, mahasiswa dapat memecahkan kesulitan belajar, dan membangun serta berbagi pengetahuan dengan lebih jelas dan detail sehingga proses pembelajaran lebih terarah dan konsep dalam matematika mudah dipahami.

Hasil penelitian mengenai pengaruh e-learning berbantuan edmodo terhadap pemahaman konsep matematika tidak jauh berbeda dengan 
DOI: https://doi.org/10.24127/ajpm.v9i4.3181

penelitian Goda (2019) yang menyatakan bahwa penggunaan edmodo dapat meningkatkan kemampuan kognitif kreatif, afektif serta hasil belajar matematika. Hasil penelitian lainnya milik Arifin \& Herman (2018) yang memaparkan bahwa proses belajar mengajar menggunakan e-learning bermodelkan web centric course memiliki pengaruh atas kemandirian dalam belajar serta pemahaman konsep matematika siswa. Penelitian berikutnya yang juga senada dilaksanakan oleh Supriatna (2018) yang memberikan hasil bahwa penerapan pembelajaran berbasis masalah menggunakan $e$ learning memiliki pengaruh signifikan dalam pemahaman konsep matematika atas ketuntasan belajar di kelas.

Berdasarkan hasil penelitian ini, pemanfaatan edmodo berpengaruh positif terhadap kemandirian belajar mahasiswa. Pengaruh positif didasarkan pada adanya peningkatan kemandirian belajar mahasiswa sebelum dan sesudah pembelajaran menggunakan edmodo. Hal ini membuktikan bahwa penggunaan edmodo pada kelas eksperimen mendapatkan respon yang lebih positif karena mampu meningkatkan kemandirian belajar mahasiswa lebih tinggi dibandingkan dengan kelas kontrol yang menggunakan WhatsApp.

Kelebihan edmodo terletak pada fitur lengkap yang dimilikinya untuk mendukung pembelajaran mandiri. Hal ini didukung oleh Dayag (2018) yang menyatakan penggunaan edmodo dapat membuat mahasiswa lebih mandiri dan bertanggungjawab terhadap tugas yang diberikan. Dengan kepraktisan yang dimiliki edmodo, meliputi tampilan yang sederhana, mendukung berbagai jenis file, dan menyediakan berbagai fitur membuat mahasiswa lebih dapat berpartisipasi aktif dan memiliki rasa percaya diri dalam pembelajaran seperti mengajukan pertanyaan dan pendapat melalui beranda, kolom komentar, pesan, maupun chat. Rasa percaya diri merupakan salah satu komponen penting dalam kemandirian belajar. Mahasiswa juga dapat melihat polling, tugas maupun kuis yang diberikan dosen dengan tenggat waktu pengumpulan yang ditetapkan sehingga mahasiswa lebih memiliki rasa tanggung jawab dan disipilin akan tugas yang mana merupakan salah satu indikator dari kemandirian belajar. Dalam penerapan edmodo selama pembelajaran, pemahaman konsep matematika mahasiswa tidak terlepas dari kemandirian belajar yang dimiliki. Sehingga untuk memahami konsep dalam matematika, kemandirian belajar sangatlah diperlukan.

Penelitian mengenai dampak edmodo pada kemandirian dalam belajar mahasiswa sejalan dengan Hatip \& Listiana (2019) yang memiliki hasil penelitian bahwa edmodo berpengaruh atas kemandirian belajar pada mahasiswa. Mahasiswa yang menerima perlakuan pembelajaran dengan edmodo memiliki nilai rata-rata kemandirian belajar yang lebih baik dengan skor 61,84 daripada mahasiswa yang tidak menggunakan e-learning berbantuan Edmodo yaitu 57.33. Penelitian lain yang dilakukan Charoenwet \& Christensen (2016) yang memiliki hasil bahwa pembelajaran dengan memanfaatkan edmodo mampu meningkatkan kemampuan belajar mandiri dalam pembelajaran online secara signifikan. Penelitian oleh Irmade \& Widjanarko (2017) juga menunjukkan hasil yang tidak jauh berbeda, yakni bahwa pembelajaran dengan memanfaatkan edmodo efektif untuk meningkatkan kemandirian dalam belajar mahasiswa. 
DOI: https://doi.org/10.24127/ajpm.v9i4.3181

Edmodo merupakan platform yang efektif bagi pembelajaran, baik untuk meningkatkan pemahaman konsep matematika maupun kemandirian belajar mahasiswa. Berbagai kelebihan yang dimiliki edmodo mampu mempengaruhi pemahaman konsep dan kemandirian belajar mahasiswa. Kendala dalam penggunaan edmodo yakni edmodo tidak banyak digunakan untuk berinteraksi langsung jika dibandingkan dengan WhatsApp. Selain itu, tingkat koneksi internet di setiap wilayah mahasiswa berbeda sehingga dapat mengakibatkan pengumpulan otomatis walaupun tugas belum selesai.

Penelitian ini memberikan implikasi yakni penggunaan e-learning berbantuan edmodo dalam meningkatkan pemahaman konsep matematika dan kemandirian belajar mahasiswa dapat menjadi pertimbangan dosen sebagai salah satu alternatif platform e-learning untuk menyampaikan materi pembelajaran. Mahasiswa cenderung memiliki kemandirian belajar yang lebih tinggi dan pemahaman konsep matematika meningkat ketika diterapkan pembelajaran menggunakan edmodo berdasarkan hasil pretest serta posttest. Hasil studi ini dapat digunakan dosen dalam usaha peningkatan pemahaman konsep matematika dan kemandirian belajar mahasiswa dengan memperhatikan kebutuhan pembelajaran agar pemahaman konsep matematika dan kemandirian belajarnya meningkat.

\section{KESIMPULAN DAN SARAN}

Bersumber dari hasil uji t dan uji MANOVA didapati kesimpulan yakni (1) Terdapat pengaruh positif edmodo terhadap pemahaman konsep matematika mahasiswa; (2) Terdapat pengaruh positif edmodo pada kemandirian dalam belajar mahasiswa; dan (3) Terdapat pengaruh positif edmodo terhadap pemahaman konsep matematika dan kemandirian belajar mahasiswa.

Adapun saran untuk para peneliti berikutnya yang akan meneliti pembelajaran dengan berbantuan edmodo adalah agar dapat mempergunakan variabel terikat lain serta menggali pengaruh pembelajaran dengan e-learning berbantuan edmodo pada kecakapan matematis yang lain.

\section{DAFTAR PUSTAKA}

Al-Said, K. M. (2015). Students' perceptions of edmodo and mobile learning and their real barriers towards them. Turkish Online Journal of Educational Technology, 14(2), 167-180.

Amalina, \& Warmansyah, J. (2020). The Implementation of E-learning Based Edmodo in Linear Algebra. International Journal of Innovation, Creativity and Change, 13(8), 284-297.

Arifin, F., \& Herman, T. (2018). Pengaruh Pembelajaran ELearning Model Web Centric Course Terhadap Pemahaman Konsep Dan Kemandirian Belajar Matematika Siswa. Jurnal Pendidikan Matematika, 12(2), 112.

Ateş Çobanoğlu, A. (2018). Student teachers' satisfaction for blended learning via Edmodo learning management system. Behaviour and Information Technology, 37(2), 133-144. https://doi.org/10.1080/0144929X. 2017.1417481

Berger, A. (2011). Self-regulation: brain, cognition, and development. Israel: Amer Psychological Assn. 
Blaustein, M. E., \& Kinniburgh, K. M. (2019). Treating Traumatic Stress in Children and Adolescents (Second Edi). NewYork: The Guilford Press. https://doi.org/10.2174/221067661 1202040313

Charoenwet, S., \& Christensen, A. (2016). The effect of Edmodo learning network on students' perception, self-regulated learning behaviors and learning performance. IMSCI 2016 - 10th International Multi-Conference on Society, Cybernetics and Informatics, Proceedings, (Imsci), 297-300.

Cheng, C. K., Paré, D. E., Collimore, L. M., \& Joordens, S. (2011). Assessing the effectiveness of a voluntary online discussion forum on improving students' course performance. Computers and Education, 56(1), 253-261. https://doi.org/10.1016/j.compedu. 2010.07.024

Collins, K. E. M. (2016). The Impact of Edmodo on Achievement and Connectedness of Middle School Students. UNION UNIVERSITY SCHOOL OF EDUCATION.

Cozad, L., \& Riccomini, P. (2016). Effects of Digital-Based Math Fluency Interventions on Learners with Math Difficulties: A Review of the Literature. The Journal of Special Education Apprenticeship, 5(2), 2.

Dayag, J. D. (2018). Reaching Out: Facilitating Efl Learning Through Edmodo. International Journal of Advanced Multidisciplinary Scientific Research (IJAMSR ISSN:2581-4281), 1(2), 1-7.

Dewi, F. (2014). EDMODO: A Social Learning Platform For Blended Learning Class in Higher
Education. Research in Education Technology, Pedagogy \& Technology, 8(1).

Edwards, S. (2007). Primary Mathematics for Teaching Assistants. New York: Routledge.

Enriquez, M. A. S. (2014). Students ' Perceptions on the Effectiveness of the Use of Edmodo as a Supplementary Tool for Learning. DLSU Research Congress, 6-11. https://doi.org/10.1017/CBO97811 07415324.004

Goda, S. H. M. (2019). Using Edmodo in Teaching MATLAB for Developing Cognitive and Affective Creative Abilities among Mathematics Department Students at Tabuk University. Journal of Educational \& Psychological Science, 20(01).

Hatip, A., \& Listiana, Y. (2019). Minat, Kemandirian Dan Hasil Belajar Mahasiswa Pendidikan Matematika Dalame-Learning Berbasis Edmodo. AKSIOMA: Jurnal Program Studi Pendidikan Matematika, 8(3), 485-496. https://doi.org/10.24127/ajpm.v8i3. 2261

Hidayati, K., \& Listyani, E. (2010). Pengembangan Instrumen Kemandirian Belajar Mahasiswa. Jurnal Penelitian dan Evaluasi Pendidikan.

https://doi.org/10.21831/pep.v14i1. 1977

Irmade, O., \& Widjanarko, P. (2017). Efektivitas Penggunaan Edmodo Terhadap Sikap Kemandirian Belajar Mahasiswa Pg-Paud Unisri Tahun Akademik 2016 / 2017. Research Fair Unisri, 1(1), 17-22.

Kilpatrick, J., \& Swafford, J. (2001). Adding It Up, Helping Children Learn Mathematics. Washington dc: National Academy Press. 
Nasrullah, A., Marlina, M., \& Dwiyanti, W. (2018). Development of student worksheet-based college e-learning through Edmodo to maximize the results of learning and motivation in economic mathematics learning. International Journal of Emerging Technologies in Learning, 13(12), 211-229.

https://doi.org/10.3991/ijet.v13i12. 8636

National Council of Teacher of Mathematics. (2000). Principle and Standars for School Mathematics. United States of America: The National Council of Teacher of Mathematics, Inc.

Ompusunggu, V. D. K., \& Sari, N. (2019). Efektifitas Penggunaan ELearning Berbasis Edmodo Terhadap Kemampuan

Komunikasi Matematika. Jurnal Curere, 3(2), 58-66. https://doi.org/10.36764/jc.v3i2.25 0

Pardede, P. (2019). EFL Theory and Practice: Voice of EED UKI. Proceeding of EED Collegiate Forum 2015-2018.

Pratama, R. A., \& Ismiyati, N. (2019). Pembelajaran Matematika Berbasis Edmodo Pada Mata Kuliah Teori Bilangan. AKSIOMA: Jurnal Program Studi Pendidikan Matematika, 8(2), 298-309.

Rittle-Johnson, B., Zippert, E. L., \& Boice, K. L. (2019). The roles of patterning and spatial skills in early mathematics development. Early Childhood Research Quarterly, 46, 166-178. https://doi.org/10.1016/j.ecresq.20 18.03.006

Sugiyono. (2016). Metode Penelitian Kuantitatif Kualitatif dan $R \& D$. Bandung: Alfabeta.
Supriatna, U. (2018). Implementasi ELearning pada Problem Based Learning (PBL) dalam Meningkatkan Kemampuan Pemahaman Konsep Matematika dan Dampaknya Terhadap Pencapaian Ketuntasan Belajar Siswa Kelas XII Madrasah Aliyah. Universitas Pasundan.

Topçu, M. S., Erbilgin, E., \& Arikan, S. (2016). Factors predicting Turkish and Korean students' science and mathematics achievement in timss 2011. Eurasia Journal of Mathematics, Science and Technology Education, 12(7), 1711-1737.

https://doi.org/10.12973/eurasia.20 $16.1530 \mathrm{a}$

Tran Ngoc Giang, N. V. M. (2014). Edmodo - A new and effective blended learning solution. Edmodo - a New and Effective Blended Learning Solution, (June), 1-6. Diambil dari http://14.161.11.88/InternationalCo nference2014/Materials/NgocGian g_VanMinh.pdf

Trust, T. (2017). Motivation, Empowerment, and Innovation: Teachers' Beliefs About How Participating in the Edmodo Math Subject Community Shapes Teaching and Learning. Journal of Research on Technology in Education, 49(1-2), 16-30. https://doi.org/10.1080/15391523.2 017.1291317 